\title{
Microwave synthesis \& sintering of Sm and Ca co-doped ceria ceramics
}

\author{
Jesús Prado-Gonjal $^{\mathrm{a}, \mathrm{b}}$, Romain Heuguet ${ }^{\mathrm{b}}$, Daniel Muñoz-Gil ${ }^{\mathrm{a}}$, \\ Alberto Rivera-Calzada ${ }^{c}$, Sylvain Marinel ${ }^{\mathrm{b}}$, Emilio Morán ${ }^{\mathrm{a}}$, \\ Rainer Schmidt ${ }^{\mathrm{c}, *}$ \\ ${ }^{a}$ Departamento de Química Inorg'anica, Facultad de Ciencias Químicas, Universidad Complutense de Madrid, 28040 \\ Madrid, Spain \\ b Laboratoire CRISMAT ENSICAEN UMR CNRS 6508, 6 boulevard du Marechal Juin, 14050 Caen Cedex 04, France

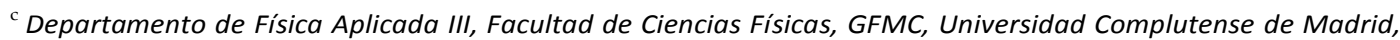 \\ 28040 Madrid, Spain
}

\section{Keywords:}

IT-SOFC

Electrolyte

Ceria

Oxygen ion conductivity

\begin{abstract}
In this work we report on the combined use of microwave (MW) heating sources for the powder synthesis and the ceramic sintering of $\mathrm{Sm}$ and $\mathrm{Ca}$ co-doped ceria $\mathrm{Ce} 0.8 \mathrm{Sm} 0.18 \mathrm{Ca} \mathrm{Ca}_{02} \mathrm{O}_{1.9}$ polycrystalline materials for potential application as an electrolyte in intermediatetemperature solid oxide fuel cells (IT-SOFCs). We investigate the crystal structure, ceramic microstructure and the oxygen ion conductivity in detail and compare the latter to conventionally sintered ceramics. MW sintering of ceramic pellets leads to only slightly increased resistivity as compared to conventional sintering, but offers massive energy and time savings for potential industrial production processes. Exceptionally high oxygen ion conductivity without any significant electronic contribution was found in MW synthesized and MW sintered pellets, where the total resistivity, composed of grain boundary and bulk contributions, was found to be in the range of $0.5-1 \mathrm{k} \Omega$ at $500^{\circ} \mathrm{C} . \mathrm{Sm}$ - and Ca co-doped ceria may be well-suited for electrolyte materials in IT-SOFCs.
\end{abstract}

\section{Introduction}

Solid oxide fuel cells (SOFCs) allow the electrochemical conversion of hydrogen and oxygen gases into electrical power and heat, and only $\mathrm{H}_{2} \mathrm{O}$ remains as a by-product. Therefore, SOFCs constitute an environmentally friendly option to replace conventional engines based on fossil fuels with problematic $\mathrm{CO}_{2}$ carbon emissions. The desired temperature

\footnotetext{
* Corresponding author.

E-mail address: rainerxschmidt@googlemail.com (R. Schmidt).
}

of operation of SOFCs depends on the application, where in the case of domestic use or in the automotive industry a reduced value is desired for practical reasons. Therefore, significant research effort is dedicated nowadays to reduce the operating temperature of current state-of-the-art SOFCs from $800-1000{ }^{\circ} \mathrm{C}$ to $500-800{ }^{\circ} \mathrm{C}$ in order to develop operational intermediate temperature SOFCs (IT-SOFCs) [1, 2]. In addition to the reduced operating temperature, ITSOFCs would be cheaper to fabricate, more rapid to startup and shut-down, 
and exhibit reduced corrosion rate of metallic components and an improved durability.

The development of an appropriate electrolyte material with sufficiently high oxygen ion conductivity at lower operating temperatures is one of the major challenges to develop IT-SOFCs. An ideal electrolyte material for IT-SOFCs should have the following characteristics [3-7]:

- High ionic and negligible electronic conductivity at the operating temperature

- Good thermal and chemical stability in relation to the adjacent anode and cathode materials

- Low cost

- Environmentally benign material characteristics

A promising choice of electrolyte materials may be the system with the fluorite-type crystal structure and chemical formula $\mathrm{AO}_{2}$, which may be considered the archetype system for materials with high oxygen ion conductivity [8-12]. The unit cell is a face-centered cubic arrangement of tetravalent Acations with oxygen anions occupying tetrahedral sites, leading to a large number of octahedral interstitial voids [13]. Thus, this structure may be regarded as a rather open one $[14,15]$. Doped ceria materials with the fluorite structure have been extensively studied as potential electrolytes in IT-SOFCs [16-20], where oxygen vacancies can be introduced into the system when $\mathrm{Ce}^{4 \mathrm{~b}}$ cations are substituted by divalent alkaline and/or trivalent rare earth (RE) cations [21-24]. Ideally, the oxygen vacancies are randomly distributed throughout the oxide sublattice, which is an essential feature required for homogenous oxygen vacancy conduction. The highest conductivity is observed at the highest oxygen vacancy concentration when the aliovalent doping cation occurs in the highest concentration possible close to the solid-solution limit, and has an ionic radius (i.r.) close to that of the host cation. In the case of $\mathrm{Ce}^{4 p}(i . r .=0.097 \mathrm{~nm})$, this may be $\mathrm{Sm}^{3 \mathrm{p}}$ (i.r. $=0.107 \mathrm{~nm}$ ) or $\mathrm{Gd}^{3 \mathrm{p}}$ (i.r. $=0.105 \mathrm{~nm}$ ) $[1,14,22-25]$ $[3,17,25-28]$. It was recently shown that (i) Sm-doped ceria ceramics provide higher oxygen ion conductivity than Gd doped or Sm-Gd co-doped ceramics, and (ii) MW chemical synthesis leads to higher ionic conductivities in the sintered pellets as compared to conventional synthesis [29,30]. Furthermore, Moure et al. have demonstrated that the resistivity of the grain boundary (GB) areas can be reduced when RE-doped ceria are co-doped with a small quantity of $\mathrm{Ca}$ $[30,31]$. The reduction of the GB resistivity is in fact essential, because the GBs constitute barriers for the oxygen ion charge transport, although they may be relatively thin. The GB barriers are often described in the framework of a Schottky-type barrier model [32].

It had been shown previously that the synthesis of nanoparticles helps to achieve better ceramic sintering densification due to the increased sintering activity of high surface area powders [19,20,33], which then leads to reduced GB resistivity. In this context, microwave-hydrothermal synthesis has emerged as a time and energy efficient technique to produce nanosized ceria-based powders for IT-SOFC applications [34-37].

Furthermore, the option to extend the use of microwave (MW) radiation as a heat source to the sintering process of ceramics has recently appeared as an additional interesting possibility to further reduce energy and time consumption in environmentally friendly ceramic processing technology [3842]. The MW sintering process works equivalent to the synthesis, where heat is generated internally in the reactants or the pressed green pellets through the interaction of the MWs on a microscopic level with atoms, ions and dipoles in the material. This produces an inverse heating profile as compared to the conventional heat transfer by heat convection, i.e. in MW heating processes the material is heated directly "from inside". By switching on the microwave radiation source, the interior areas of the sample will be heated first but the heating profile becomes more uniform after few seconds of MW irradiation and the outer areas will be heated as well [43].

In the present work, microwave-hydrothermal nanopowder synthesis and single-mode MW ceramic sintering as well as conventional sintering of optimally doped $\mathrm{Ce}_{0.8} \mathrm{Sm}_{0.18} \mathrm{Ca}_{0.02} \mathrm{O}_{1.9}$ materials are studied in detail, including structural and microstructural characterization, and ionic conductivity measurements of the resulting ceramic pellets. Throughout this work it was intended to utilize all possible means to reduce the GB barrier resistivity as much as possible to optimize the overall ionic conductivity:

(a) Synthesizing nanopowders with increased sintering activity using MW heating

(b) Use the preferred Sm cation for RE-doping

(c) Apply additional Ca doping to a small extent

By following this strategy we obtain ceramics with oxygen ion conductivities that are among the highest values reported so far in ceramic oxygen ion conductors [30]. Therefore, MW synthesized and MW sintered $\mathrm{Ce}_{0.8} \mathrm{Sm}_{0.18} \mathrm{Ca}_{0.02} \mathrm{O}_{1.9}$ ceramics may be strong candidates for the use as electrolyte materials in IT-SOFCs.

\section{Experimental procedure}

\section{Synthesis}

The synthetic procedure for $\mathrm{Ce}_{0.8} \mathrm{Sm}_{0.18} \mathrm{Ca}_{0.02} \mathrm{O}_{1.9}$ is equivalent to the one described previously in Ref. [26] for different REdoped ceria. Here, the starting chemicals were Cerium (III) nitrate hexahydrate $\mathrm{Ce}\left(\mathrm{NO}_{3}\right)_{3} \cdot 6 \mathrm{H}_{2} \mathrm{O}, \geq 99 \%$ (Sigma-Aldrich), Samarium (III) nitrate hexahydrate $\mathrm{Sm}\left(\mathrm{NO}_{3}\right)_{3} \cdot 6 \mathrm{H}_{2} \mathrm{O}, 99.9 \%$ (Sigma-Aldrich), Calcium (II) nitrate tetrahydrate $\mathrm{Ca}(\mathrm{N}-$ $\left.\mathrm{O}_{3}\right)_{2} \cdot 4 \mathrm{H}_{2} \mathrm{O}, \geq 99 \%$ (Sigma-Aldrich) and Potassium hydroxide $\mathrm{KOH}$ flakes, $90 \%$ (Sigma-Aldrich). Aqueous solutions were prepared by dissolving the nitrate salt in the desired ratios in distilled water and 1.2 M KOH under constant stirring. In a typical experiment $\approx 40 \mathrm{ml}$ solution was produced, which was then ultrasonically dispersed for $2 \mathrm{~min}$. The synthesis reactions were carried out in double-walled vessels consisting of an inner Teflon sealed autoclave and an outer shell of high strength polymer. The double-walled vessels were placed in a commercial Milestone ETHOS 1 microwave system, which was operated at $2.45 \mathrm{GHz}$ and was equipped with a stirring motor. The heating ramp up to $200^{\circ} \mathrm{C}$ was $\approx 10^{\circ} \mathrm{C} / \mathrm{min}$ and the 
holding time at $200{ }^{\circ} \mathrm{C}$ was $30 \mathrm{~min}$, which was followed by switching off the microwave power to furnace cool to room temperature at $\approx 5{ }^{\circ} \mathrm{C} / \mathrm{min}$. The reaction vessels were connected to a pressure transducer in order to monitor the autogenous pressure, which was found to amount to $\approx 16$ bars during the $30 \mathrm{~min}$ holding time at $200^{\circ} \mathrm{C}$. Power was limited to $500 \mathrm{~W}$. The crystallized powder obtained was decanted 3 times, rinsed with distilled water and dried at $80^{\circ} \mathrm{C}$.

\section{Sintering process}

Two different sintering processes have been employed. In both cases, MW synthesized nano-powders were compacted into pellets in a uni-axial 2 ton die press for 5 min with a nominal diameter of $5 \mathrm{~mm}$ and green-pellet thicknesses of around $2 \mathrm{~mm}$ were obtained.

1) In the first instance densification sintering was carried out at $1450{ }^{\circ} \mathrm{C}$ (heating ramp $5^{\circ} \mathrm{C} / \mathrm{min}$ ) in a conventional furnace for either $4 \mathrm{~h}$ or $8 \mathrm{~h}$ followed by slow cooling with a cooling rate of $\approx 1.5^{\circ} \mathrm{C} / \mathrm{min}$.

2) Alternatively, the pellets were placed into a crucible made of $\mathrm{SiC}$, which strongly absorbs microwaves to improve the heating process. The $\mathrm{SiC}$ crucible was partially filled with $\mathrm{Ce}_{0.8} \mathrm{Sm}_{0.18} \mathrm{Ca}_{0.02} \mathrm{O}_{1.9}$ powder to avoid direct contact of the green pellet and the SiC to avoid cross-contamination. MW sintering was performed using different holding times of 5, 30 and $60 \mathrm{~min}$ in a single-mode microwave applicator (SAIREMCompany) working at $2.45 \mathrm{GHz}$. The radiation was guided along a commercial $\mathrm{TE}_{10 \mathrm{p}}$ waveguide equipped with two circulators that absorb the reflected power to protect the generator. The length of the microwave cavity was tuned to excite the $\mathrm{TE}_{102}$ mode. The temperature was measured using a pyrometer (modline 5 from IRCON from $350{ }^{\circ} \mathrm{C}$ to $2000^{\circ} \mathrm{C}$ ) focused on the sample surface. The thermal cycle included a ramp of $\approx 300^{\circ} \mathrm{C} / \mathrm{min}$ and holding at $1450{ }^{\circ} \mathrm{C}$ by adjusting the 3 stub tuners and the incident power. The incident power to achieve $\approx 1450{ }^{\circ} \mathrm{C}$ was $\approx 300 \mathrm{~W}$. After the desired holding time at $1450{ }^{\circ} \mathrm{C}$ (from $5 \mathrm{~min}-60 \mathrm{~min}$ ), the power was switched off and the sample was cooled down to room temperature.

In both sintering procedures, the density of the obtained pellets was estimated from the pellet dimensions to be satisfactory in the range of $\approx 95 \% \pm 5 \%$ of the theoretical density.

\section{Characterization}

\section{Structural and microstructural characterization}

Powder X-ray diffraction (XRD) patterns were collected on a Philips XPert PRO ALPHA1 of Panalytical B.V. diffractometer with Cu Ka1 monochromatic radiation $(\lambda=1.54056$ Å) equipped with a curved Ge111 primary beam monochromator and a speed $X^{\prime}$ Celerator fast detector, operating at $45 \mathrm{kV}$ and $40 \mathrm{~mA}$. The diffractometer is calibrated weekly by recording data from a standard $\mathrm{Si}$ powder to exclude any experimental artefacts. XRD patterns were collected in the $2 \theta$ range of $20-120^{\circ}$ at room temperature with an angle step size of $0.017^{\circ}(2 \theta)$ and $8 \mathrm{sec}$ counting time to ensure sufficient resolution for structural refinements. Fullprof software was employed to carry out structural refinements from the XRD patterns employing Rietveld refinement analysis [44].

Samples for transmission electron microscopy (TEM) were prepared by ultrasonic dispersion of the powder in n-butanol. Drops of this dispersion were deposited on a carbon-coated copper grid. A Jeol-2000FX electron microscope operating at $200 \mathrm{kV}$ was used to collect bright field images and perform selected area electron diffraction (SAED). Sintered pellet samples were mounted on metal studs and were dc sputter coated with Au (EMITECH K550) for scanning electron microscopy (SEM) using a Jeol 6400 microscope equipped with an attached detector for energy-dispersive analysis of X-rays (EDAX).

Specific surface area (SSA) measurements were carried out by the Brunauer, Emmett and Teller (BET) method [45]. Nitrogen adsorption-desorption isotherms were recorded using a Micromeritics ASAP 200 surface analyzer at $77 \mathrm{~K}\left(-196{ }^{\circ} \mathrm{C}\right)$. Prior to the measurements the powder samples were placed in a glass cell and heated in vacuum at $110^{\circ} \mathrm{C}$ for $180 \mathrm{~min}$ in order to achieve the removal of water and other contaminants by degassing which is essential to facilitate accurate surface area determination. The BET analysis port was cooled by immersion into a liquid nitrogen dewar to maintain the temperature of $77 \mathrm{~K}\left(-196^{\circ} \mathrm{C}\right)$ during the measurement. The low temperature is required to ensure sufficient interaction between the gas molecules and the surface of the sample for measurable amounts of nitrogen adsorption to occur. Nitrogen adsorption layers were formed on the particle surfaces, the sample was removed from the nitrogen atmosphere and the release of the adsorbed nitrogen was quantified during heating. The data collected were displayed in the form of BET isotherms, which show the amount of gas adsorbed as a function of the relative pressure [46].

\section{lonic conductivity measurements}

For ionic conductivity measurements by impedance spectroscopy (IS), electrodes were deposited onto the two faces of the sintered pellets using Au dc sputtering and were covered with Ag paint. IS measurements were carried out at $400 \mathrm{~K}$ $560 \mathrm{~K}\left(127^{\circ} \mathrm{C}-287^{\circ} \mathrm{C}\right)$ using a Novocontrol Alpha-A High Performance Frequency Analyzer equipped with a liquid nitrogen cooled sample chamber. A $100 \mathrm{mV}$ amplitude alternating voltage signal of various frequency $(f)$ between $1 \mathrm{~Hz}$ - $1 \mathrm{MHz}$ was employed. IS measurements at $573 \mathrm{~K}-873 \mathrm{~K}$ $\left(300{ }^{\circ} \mathrm{C}-600{ }^{\circ} \mathrm{C}\right)$ were carried out using a Solartron SI 1255 equipped with a Dielectric Interface 1296 and a Eurotherm controlled tube furnace. A $100 \mathrm{mV}$ amplitude alternating voltage signal of various frequency $(f)$ between $0.1 \mathrm{~Hz}-1$ $\mathrm{MHz}$ was employed.

At selected temperatures the $f$-dependent spectra were measured with several dc bias voltages $(0 \mathrm{~V}-20 \mathrm{~V})$, which were superimposed over the ac amplitude using the standard routine available from the Novocontrol equipment. Furthermore, the impedance was measured at different gas flow atmospheres using $\mathrm{N}_{2}$ rich gas flow and air gas flow. In each case the sample was exposed to the gas flow for $\approx 30 \mathrm{~min}$ prior to the measurements. The impedance was then measured at selected temperatures to detect the possible reduction or oxidation of the $\mathrm{Ce}^{3+} / \mathrm{Ce}^{4+}$ redox pair, which would be manifested by a change in resistance. 
IS data were obtained at each temperature in terms of the real and imaginary parts $\left(Z^{\prime}, Z^{\prime \prime}\right)$ of the complex impedance $Z^{*}=Z^{\prime}-\mathrm{i} Z^{\prime \prime}$. The data were converted into the complex dielectric permittivity notation $\varepsilon^{*}=\varepsilon^{\prime}-\mathrm{i} \varepsilon^{\prime \prime}$ using the standard conversion: $Z^{*}=\left(i \omega C_{0} \varepsilon^{*}\right)^{-1}$, where $\omega$ is the angular frequency and $C_{0}$ the capacitance of the empty measuring cell. Equivalent circuit fitting of the data obtained was performed by using Z-View software. The values extracted from the equivalent circuit fits were plotted vs temperature in various notations (see below Section 3.2), but only the values were considered that were extracted from a good fit with sufficiently low fitting errors $(<5 \%)$.

\section{Results and discussion}

\section{Structural and microstructural characterization}

The XRD pattern of $\mathrm{Ce}_{0.8} \mathrm{Sm}_{0.18} \mathrm{Ca}_{0.02} \mathrm{O}_{1.9}$ powder is shown in Fig. 1 (red symbols), as well as the Rietveld refinement fit (black solid line) and the difference between data and model (blue solid line underneath). Phase purity and the fluorite $\mathrm{CeO}_{2}$ crystal structure were confirmed. The diffraction peaks were indexed to the cubic Fm-3m (\#225) space group. The perceptible diffraction line broadening is consistent with the nanometric size of the MW synthesized powder, which is confirmed in the TEM picture presented in Fig. 2. The cell parameter obtained from the Rietveld refinement is $a=$ 5.4372(1) $\AA$. The atom positions are all fixed by the symmetry of the $\mathrm{Fm}-3 \mathrm{~m}$ space group. $\mathrm{Sm}^{3+}$ and $\mathrm{Ca}^{2+}$ cations are situated at the $4 \mathrm{a}$ site with the atomic coordinate $(0,0,0)$ and oxygen is at the $8 \mathrm{c}$ site corresponding to the $(1 / 4,1 / 4,1 / 4)$ position. The agreement factors of $R_{\mathrm{p}}=2.38, R_{\mathrm{wp}}=3.31, R_{\exp }=2.69$ and $\chi^{2}=1.52$ were sufficiently low to indicate a good fit.

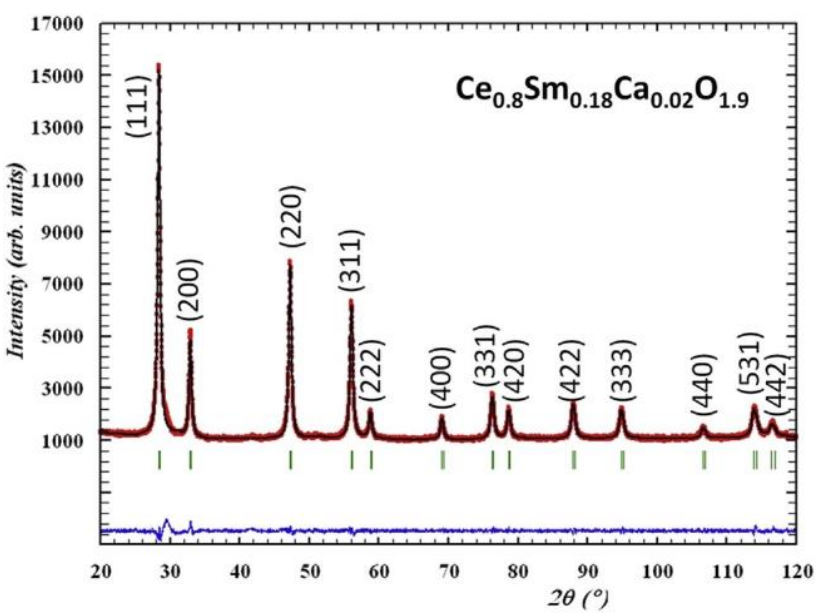

Fig. 1 - Rietveld refinement of powder X-ray diffraction patterns: experimental data (red dotted line), fitted curve (black solid line), and their difference (blue line underneath). Green vertical bars indicate the positions of the X-ray reflections.

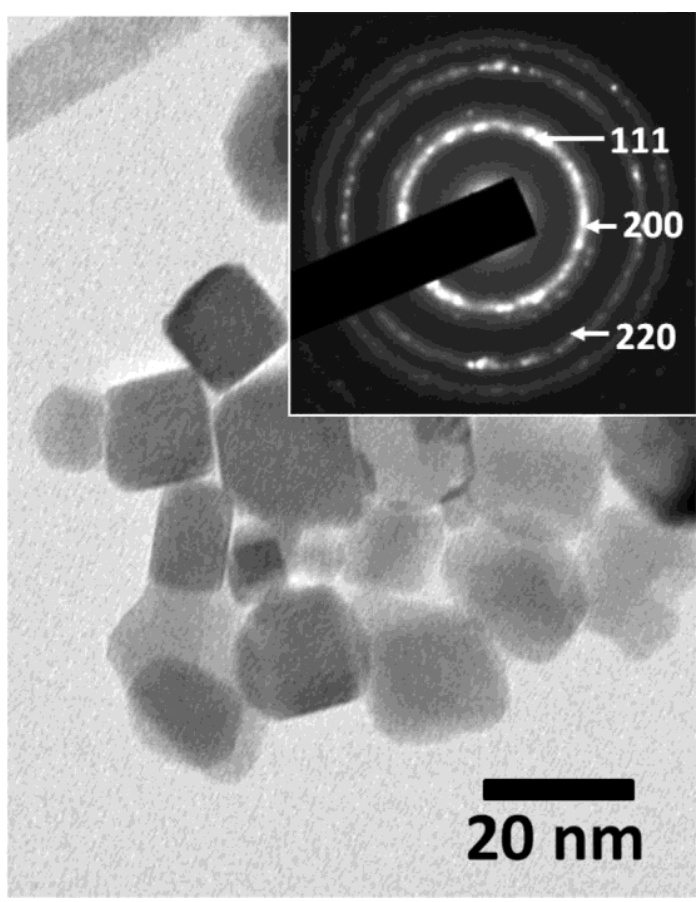

Fig. 2 - TEM micrograph of $\mathrm{Ce}_{0.8} \mathrm{Sm}_{0.18} \mathrm{Ca}_{0.02} \mathrm{O}_{1.9}$ nanopowder. Inset: SAED pattern.

Fig. 2 shows a TEM image from the MW synthesized powder. All particles are in the nanometric range with an average particle size of less than $20 \mathrm{~nm}$. The corresponding EDAX microanalysis from a larger area containing several grains reveals experimental $\mathrm{Ce}, \mathrm{Ca}$ and $\mathrm{Sm}$ atomic proportions of $80.1(2) \%, 2.3(1) \%$ and $17.6(2) \%$ respectively, which are in good agreement with the nominal ones $(80 \%, 2 \%$ and $18 \%$ ) within experimental error.

BET analysis of the powder yielded a specific surface area of $57.4(1) \mathrm{m}^{2} / \mathrm{g}$, in good agreement with the powder obtained previously by microwave-hydrothermal synthesis of other REdoped ceria [45]. The BET nitrogen absorption isotherm

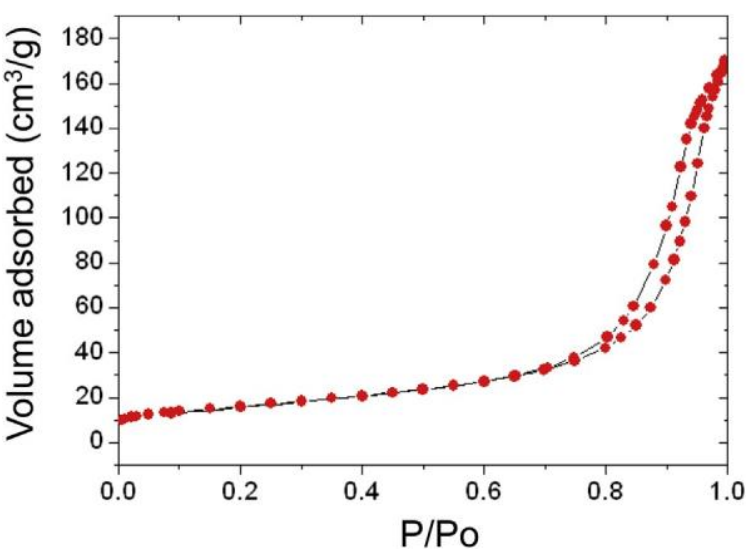

Fig. 3 -BET $\mathrm{N}_{2}$ adsorptionedesorption isotherms at $77 \mathrm{~K}$ $\left(-196{ }^{\circ} \mathrm{C}\right)$ for $\mathrm{Ce}_{0.8} \mathrm{Sm}_{0.18} \mathrm{Ca}_{0.02} \mathrm{O}_{1.9}$ nano-powder. The amount of gas adsorbed and desorbed $\left(\mathrm{cm}^{3} \mathrm{~g}^{-1}\right)$ is plotted vs. the relative pressure $\left(P / P_{0}\right)$ 
presented in Fig. 3 corresponds to type IV, which is the typical isotherm for mesoporous materials [47]. The isotherm exhibits a hysteresis loop, where the lower branch represents measurements obtained by progressive addition of gas to the adsorbent, and the upper branch by progressive withdrawal. Such hysteresis is usually associated with mesoporous materials, which exhibit pores of the size of $2 \mathrm{~nm}-50 \mathrm{~nm}$, according to the definition from the International Union of Pure and Applied Chemistry (IUPAC) [48]. Our particles have a size of $\approx 20 \mathrm{~nm}$, which implies a relatively large pore size as compared to the total particle size. We believe that smaller pores $<2 \mathrm{~nm}$ may also exist in our particles to a certain extent, in which case our particles may be just on the brink of the classification as a mesoporous rather than a microporous material.

The microstructure of the sintered pellets is shown in the SEM micrographs in Fig. 4, which were chosen to be good representations for the total sample. For all the different sintering procedures employed, the pellets indicate a dense microstructure and relatively uniform grain size. Grain growth was indicated in terms of an increase in the mean grain size when the microwave irradiation time was increased (Fig. 5). The smaller grains visible on the surface of the MW sintered pellets (Fig. 4) can be associated with the $\mathrm{Ce}_{0.8} \mathrm{Sm}_{0.18} \mathrm{Ca}_{0.02} \mathrm{O}_{1.9}$ powder that was used to physically separate the green pellet and the $\mathrm{SiC}$ crucible to avoid crosscontamination during sintering.

\section{Ionic conductivity measurements by impedance spectroscopy}

\section{Equivalent circuit fitting}

Fig. 6 displays a complex impedance plane plot of imaginary vs real part of the impedance $-Z^{\prime \prime}$ vs $Z^{\prime}$ collected at $440 \mathrm{~K}$ $\left(167^{\circ} \mathrm{C}\right)$ from an $8 \mathrm{~h}$ conventionally sintered ceramic pellet with composition $\mathrm{Ce}_{0.8} \mathrm{Sm}_{0.18} \mathrm{Ca}_{0.02} \mathrm{O}_{1.9}$. The figure inset

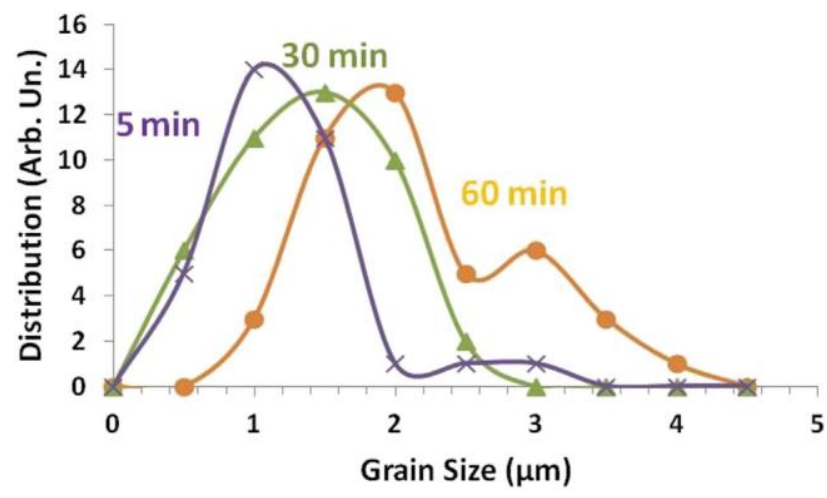

Fig. 5 - Grain size distributions obtained from the SEM micrographs shown in Fig. 4.

displays the equivalent plot at $523 \mathrm{~K}\left(250^{\circ} \mathrm{C}\right)$ for a ceramic of the same composition but MW sintered for $30 \mathrm{~min}$. The two semicircles displayed for each sample represent the bulk and GB contributions, whereas the pike-like shape of the low frequency interface contribution ("Interface Pike") is a manifestation of the typical blocking type electrodes in ionic conductors $[49,50]$. The $-Z^{\prime \prime}$ vs $Z^{\prime}$ complex impedance plots for all other samples (not shown) display the equivalent low frequency "interface pike", typical for oxygen ion conductivity. In the MW sintered sample (Fig. 6 Inset) considerable overlap between the GB semicircle and the interface-pike is shown, in a way that the GB semicircle is not fully developed.

All 3 relaxation processes (bulk, GB, interface) are clearly visible at the same time only around the selected temperatures of $440-523 \mathrm{~K}$. By increasing the temperature all dielectric relaxations shift to higher frequencies, because all 3 relaxation processes are Arrhenius activated and get accelerated at
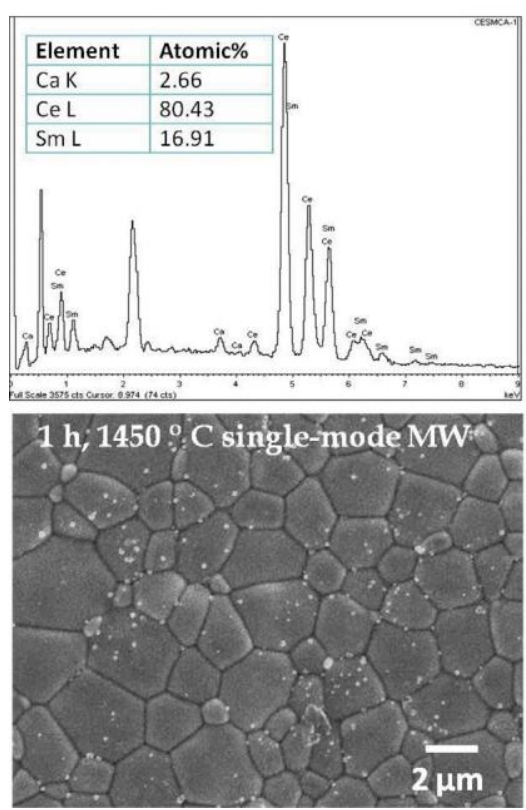
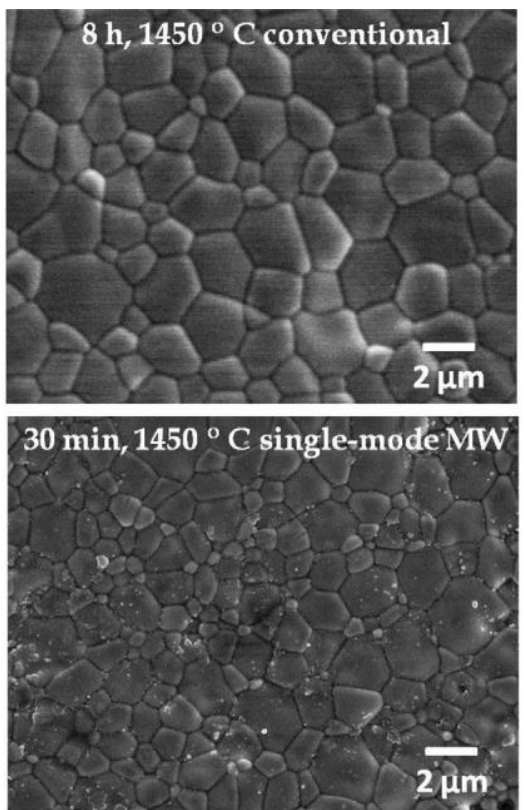
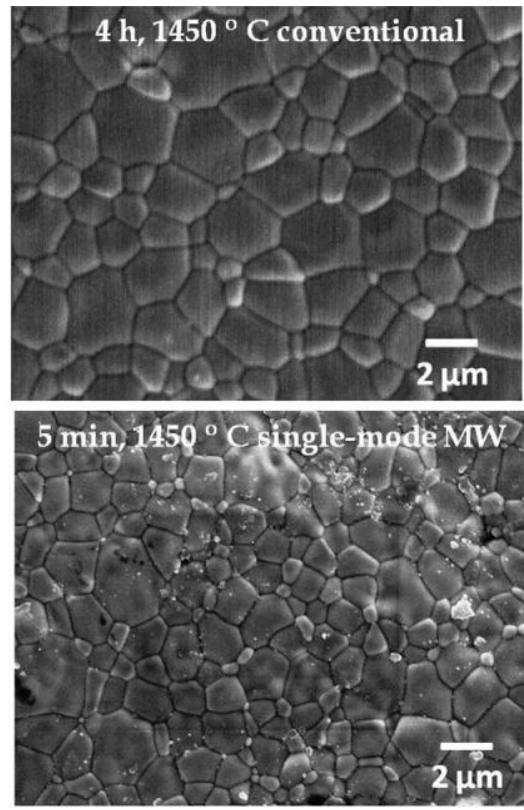

Fig. 4 - EDAX spectrum of a $\mathrm{Ce}_{0.8} \mathrm{Sm}_{0.18} \mathrm{Ca}_{0.02} \mathrm{O}_{1.9}$ ceramic for elemental detection. SEM micrographs of conventionally sintered pellets at $1450{ }^{\circ} \mathrm{C}$ for $8 \mathrm{~h}$ and $4 \mathrm{~h}$ (upper row), and MW sintered pellets for 60, 30 and 5 min (lower row). 


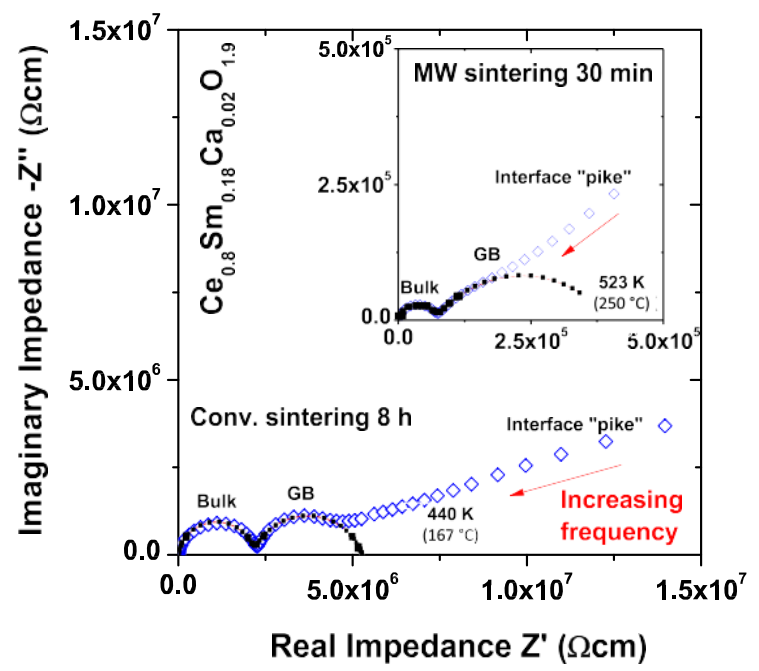

Fig. 6 - Complex impedance plot of $-Z^{\prime \prime}$ vs. $Z$ at $440 \mathrm{~K}(167$ ${ }^{\circ} \mathrm{C}$ ) for a $\mathrm{Ce}_{0.8} \mathrm{Sm}_{0.18} \mathrm{Ca}_{0.02} \mathrm{O}_{1.9}$ ceramic sintered conventionally at $1450{ }^{\circ} \mathrm{C}$ for $8 \mathrm{~h}$. Inset: $-Z^{\prime \prime}$ vs. $Z$ at $523 \mathrm{~K}$ $\left(250{ }^{\circ} \mathrm{C}\right.$ ) for $\mathrm{Ce}_{0.8} \mathrm{Sm}_{0.18} \mathrm{Ca}_{0.02} \mathrm{O}_{1.9} \mathrm{MW}$ sintered for $30 \mathrm{~min}$. The plots in the main figure and in the figure inset both demonstrate bulk, GB and interface contributions. Open symbols ( represent measured data, squares and solid lines represent equivalent circuit fits at intermediate/ high frequency using two series R-CPE elements.

higher temperature [29]. This implies that the high frequency bulk relaxation will gradually disappear and finally completely fall out of the high frequency measurement limit by increasing the temperature. Ultimately, the bulk semicircle would not be visible anymore, but the non-zero intercept of the data with the real $Z^{\prime}$ axis would still allow us determining the bulk resistivity at elevated temperatures whereas the bulk dielectric permittivity would not be accessible anymore. In the same way, the interface-pike and then the GB relaxation would disappear gradually below the low frequency measurement limit by reducing the measurement temperature.

The standard equivalent circuit model of two non-ideal resistor-capacitor (RC) elements [29] was used to fit the data at various temperatures at intermediate and high frequencies where the bulk and GB relaxations are dominant. The bulk and GB contributions were each represented by one non-ideal $\mathrm{RC}$ element, and the two are then connected in series. The ideal capacitor in each $\mathrm{RC}$ element had been replaced by a constant phase element (CPE) [50], which accounts for the non-ideality of the respective dielectric relaxation process. On a microscopic level the CPE behavior is usually explained in the framework of a jump-relaxation model [51], or in simpler terms by a broadening of the distribution of relaxation times $\tau$ across the sample [52], where $\tau=R \cdot C$, with $R$ being the resistance and $C$ the capacitance of an ideal $R C$ element [53]. In the $-Z^{\prime \prime}$ vs $Z^{\prime}$ data (Fig. 6), the CPE behavior is manifested by the impedance semicircles which have their semicircle centers slightly suppressed below the real $Z^{\prime}$-axis. In the data set for the MW sintered sample (Fig. 6 Inset) the GB semicircle seems to be slightly more suppressed, which can be associated with a higher "non-ideality" of the dielectric relaxation process and a broader distribution of $\tau$. A more obvious manifestation of the CPE behavior is shown below (Fig. 8), using the notation of $\varepsilon^{\prime}$ vs $f$.

An almost ideal fit of the data was obtained at intermediate and high frequencies using 2 R-CPE elements in series, whereas at lower $f$ the interface contribution is not accounted for and the GB values from the fits were extrapolated to lower $f$ values (Fig. 6). The blocking type interface could not be modelled with standard RC or R-CPE elements, because its resistance is dominated by diffusion processes that do not follow the behavior of resistors or capacitors.

The temperature dependence of the ionic charge transport is illustrated in Fig. 7 for the $\mathrm{Ce}_{0.8} \mathrm{Sm}_{0.18} \mathrm{Ca}_{0.02} \mathrm{O}_{1.9}$ ceramic sample sintered conventionally at $1450{ }^{\circ} \mathrm{C}$ for $4 \mathrm{~h}$, where the data are represented in the notation of the imaginary part of the impedance $-Z^{\prime \prime}$ vs $f$. The height of the bulk and GB relaxation peaks displayed is proportional to the resistance of the respective $\mathrm{R}-\mathrm{CPE}$ element, and the thermal activation of bulk and GB ionic charge transport is demonstrated by solid lines in Fig. 7. In the intermediate and high frequency regime where the bulk and GB contributions are dominant, the equivalent circuit model and the data show again excellent agreement.

The same $-z$ "vs $f$ plots for all other samples (not shown) display the equivalent features.

The data represented in Fig. 8 were collected from the

$\mathrm{Ce}_{0.8} \mathrm{Sm}_{0.18} \mathrm{Ca}_{0.02} \mathrm{O}_{1.9}$ ceramic sample sintered by MW for $5 \mathrm{~min}$. The data are plotted in the format of the dielectric permittivity $\varepsilon^{\prime}$ vs $f$. Again, three distinct regimes are displayed, which were assigned to bulk, GB and interface contributions. The bulk and GB contributions are manifested by one slightly frequency dependent $\varepsilon$ ' plateau each as indicated by the blue

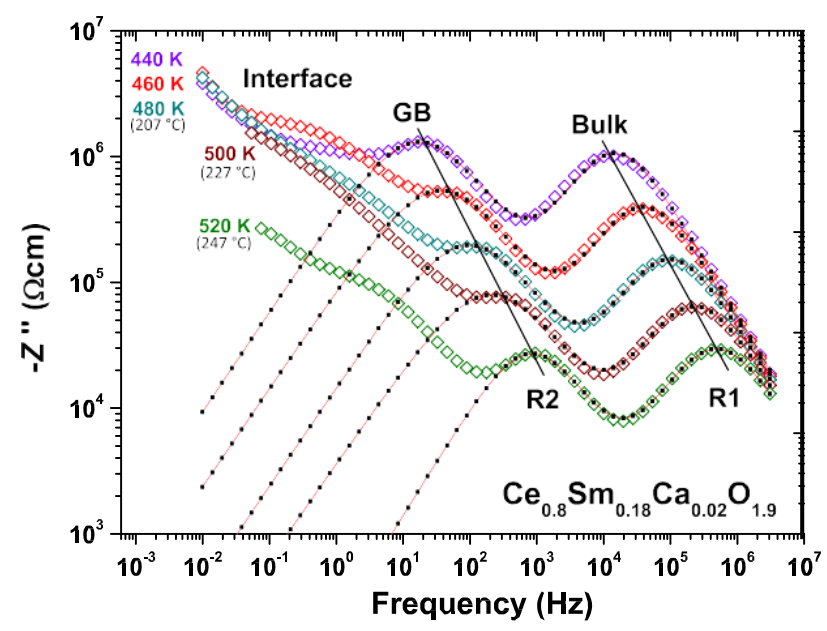

Fig. 7 - Imaginary part of the impedance $\left(-Z^{\prime}\right)$ plotted vs. frequency for a $\mathrm{Ce}_{0.8} \mathrm{Sm}_{0.18} \mathrm{Ca}_{0.02} \mathrm{O}_{1.9}$ ceramic sintered conventionally at $1450{ }^{\circ} \mathrm{C}$ for $4 \mathrm{~h}$. Two dielectric relaxation peaks for the GB and bulk dielectric contributions are displayed. Both peaks exhibit thermal activation as indicated by the solid lines. Open symbols represent measured data, squares and solid lines represent equivalent circuit fits using the equivalent circuit model based on a series of two R-CPE elements. Data were collected at $440 \mathrm{~K}$ $\left(167^{\circ} \mathrm{C}\right), 460 \mathrm{~K}\left(187^{\circ} \mathrm{C}\right), 480 \mathrm{~K}\left(207^{\circ} \mathrm{C}\right)$, $500 \mathrm{~K}\left(227^{\circ} \mathrm{C}\right)$ and $520 \mathrm{~K}\left(247^{\circ} \mathrm{C}\right)$. 


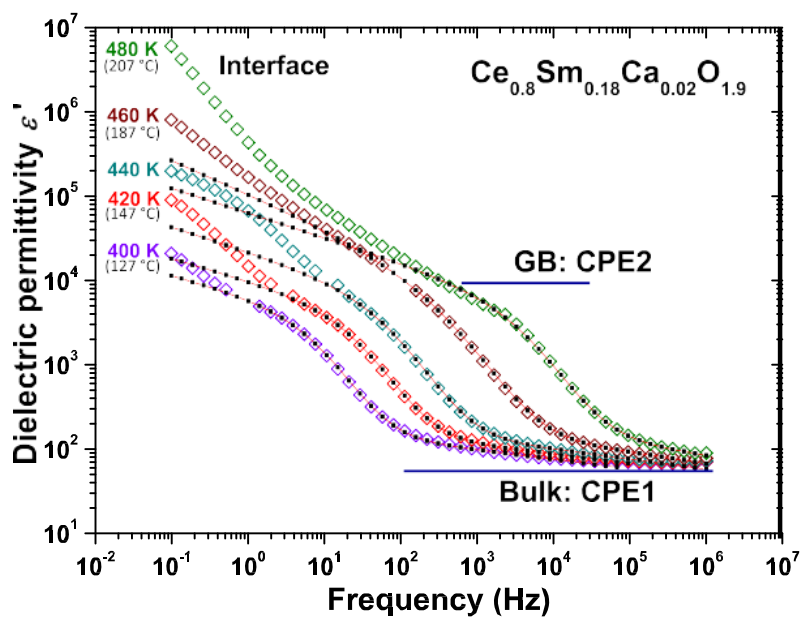

Fig. 8 - Relative dielectric permittivity $\varepsilon^{\prime}$ vs. $f$ for $\mathrm{Ce}_{0.8} \mathrm{Sm}_{0.18} \mathrm{Ca}_{0.02} \mathrm{O}_{1.9}$ ceramics sintered with $\mathrm{MW}$ techniques at $1450{ }^{\circ} \mathrm{C}$ for $5 \mathrm{~min}$. Open symbols represent measured data, squares and solid lines represent equivalent circuit fits to the data using the equivalent circuit model based on a series of two R-CPE elements. Data were collected at $400 \mathrm{~K}\left(127^{\circ} \mathrm{C}\right), 420 \mathrm{~K}$ $\left(147^{\circ} \mathrm{C}\right), 440 \mathrm{~K}\left(167^{\circ} \mathrm{C}\right), 460 \mathrm{~K}\left(187^{\circ} \mathrm{C}\right)$ and $480 \mathrm{~K}\left(207^{\circ} \mathrm{C}\right)$. The blue solid lines are guide to the eye to visualize the bulk and GB capacitance plateaus.

solid lines in Fig. 8; the bulk plateau at high $f$ and the GB plateau at intermediate $f$. The $f$-dependence of these plateaus, especially for the GB contribution, is now a quite clear manifestation for the CPE behavior, whereas for ideal RC elements the two plateaus would be strictly $f$-independent.

The step-like decrease from the intermediate- $f$ to the high$f$ plateau is expected for two conventional dielectric contributions in ionic conductors, as compared to interface contributions that are dominated by diffusion processes. The electrode interface contribution appears in Fig. 8 at the low $-f$ end in form of a continuous increase of $\varepsilon^{\prime}$ with decreasing $f$, which cannot be represented by standard equivalent circuits based on RC or R-CPE elements. This uniform slope of the $\varepsilon^{\prime}$ vs $f$ curve at low $f$ in Fig. 8 is again the typical behavior of a blocking electrode interface and suggests that the charge carriers are oxygen ions. The $\varepsilon^{\prime}$ vs $f$ plots for all other samples (not shown) display the equivalent uniform slope in $\varepsilon^{\prime}$ vs $f$ at low $f$, typical for oxygen ion conductivity.

The equivalent circuit fitting procedure was repeated on data collected at various temperatures, atmospheres and under several super-imposed dc-biases. In this way, the temperature, atmosphere and dc-bias dependence of the bulk and GB resistance and capacitance can be determined, where their values at various temperatures can be extracted from the equivalent circuit resistors and capacitors.

\section{Resistivity data}

The GB and bulk resistance values from the equivalent circuit model were converted into resistivity $\rho$ by taking into account the pellet dimensions. The temperature dependence of the GB and bulk resistivity are displayed in Figs. 9 and 10 respectively, for a Sm-doped $\mathrm{Ce}_{0.85} \mathrm{Sm}_{0.15} \mathrm{O}_{1.925}$ ceramic sintered conventionally for $4 \mathrm{~h}$ at $1450{ }^{\circ} \mathrm{C}$ and for co-doped $\mathrm{Ce}_{0.8} \mathrm{Sm}_{0.18} \mathrm{Ca}_{0.02} \mathrm{O}_{1.9}$ ceramics sintered under various conditions (see figure caption). The activation energies $\left(E_{\mathrm{A}}\right)$ were determined from the slope of the respective Arrhenius plots, giving approximate values of $E_{\mathrm{A}} \approx 0.9-1 \mathrm{eV}$ for the GBs, and $E_{\mathrm{A}} \approx 0.85-0.95 \mathrm{eV}$ for the bulk, which are typical values for bulk and GB oxygen ion charge transport in doped ceria [15,29,30,54]. The total resistivity and conductivity values, composed of GB and bulk contributions, at $300{ }^{\circ} \mathrm{C}$ and $500{ }^{\circ} \mathrm{C}$, and all $E_{\mathrm{A}}$ values are summarized in Table 1 . The $E_{\mathrm{A}}$ values are given in $\mathrm{eV}$ and additionally in $\mathrm{K}$, where the latter refers to the thermal activation energy given as a characteristic temperature $T_{0}$, which is connected to the former via $E_{\mathrm{A}}=$ $k_{\mathrm{B}} T_{0}$. The GB resistivity displayed in Fig. 9 shows a clear reduction with the $\mathrm{Ca}$ doping, in contrast to the intrinsic bulk resistivity (Fig. 10), which is affected only marginally by Ca doping. From our Figs. 9 and 10 it can be deduced that Ca doping effectively reduces the GB resistance without any significant changes to the intrinsic bulk resistance in the grain interior areas.

The GBs in oxygen ion conducting RE-doped ceria are commonly interpreted as Schottky-type barriers [32,55], impeding higher oxygen ion conductivities. However, we refrain from the quantitative application of the Schottkybarrier model to our polycrystalline ceramics for extracting the barrier height and width, because it may not be reliable. This is a well-known and long-standing issue in polycrystalline ionic conductors and may arise from the existence of multiple grain boundaries, varying grain boundary

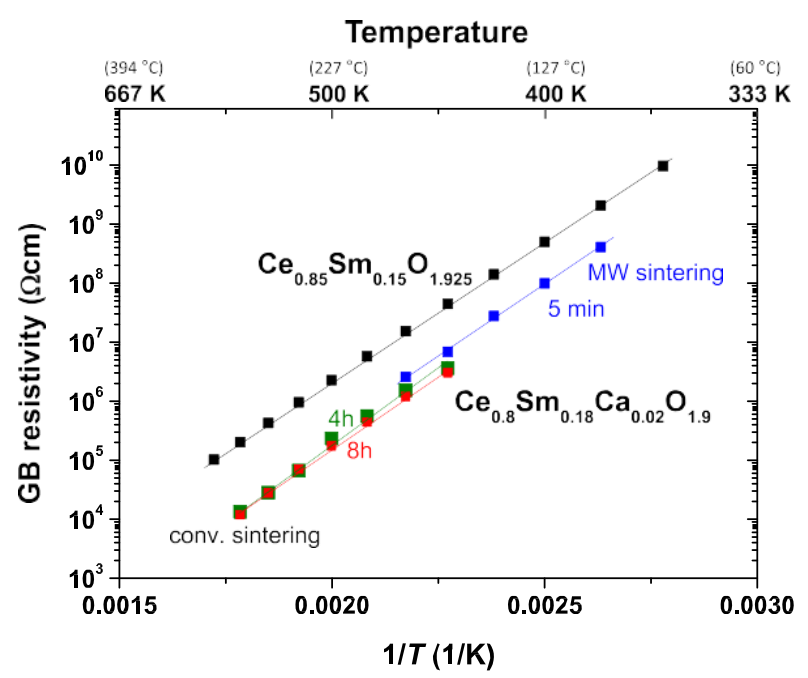

Fig. 9 - GB resistivity values from equivalent circuit fits for ceramic $\mathrm{Ce}_{0.85} \mathrm{Sm}_{0.15} \mathrm{O}_{1.9}$ ceramics sintered conventionally for $4 \mathrm{~h}$ (black), and $\mathrm{Ce}_{0.8} \mathrm{Sm}_{0.18} \mathrm{Ca}_{0.02} \mathrm{O}_{1.9}$ ceramics sintered conventionally for $4 \mathrm{~h}$ (green) and $8 \mathrm{~h}$ (red) and sintered with MWs for $5 \mathrm{~min}$ (blue). The resistivity values were obtained from the respective resistor in the equivalent circuit model and are plotted vs. reciprocal temperature $1 / T$. 


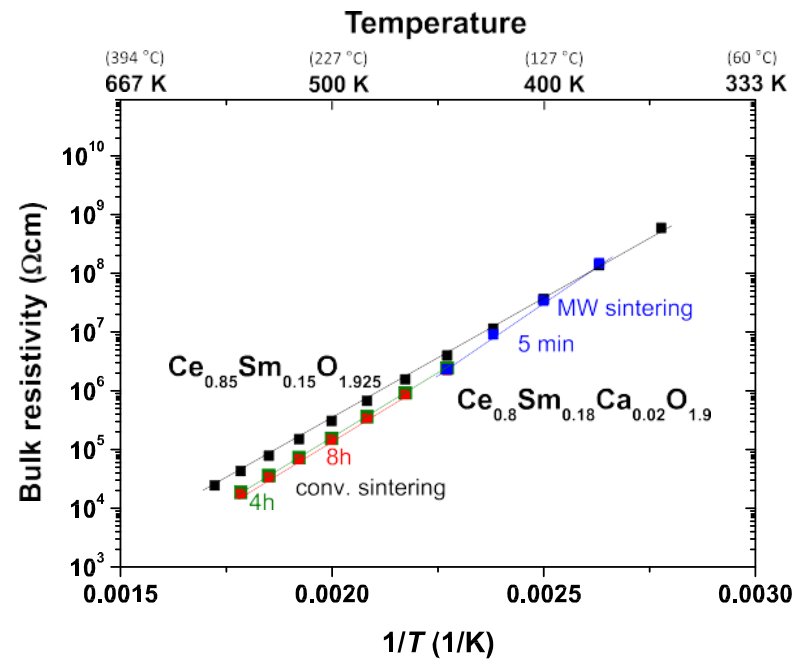

Fig. 10 - Bulk resistivity values from equivalent circuit fits for $\mathrm{Ce}_{0.85} \mathrm{Sm}_{0.15} \mathrm{O}_{1.925}$ ceramics sintered conventionally for $4 \mathrm{~h}$ (black), and $\mathrm{Ce}_{0.8} \mathrm{Sm}_{0.18} \mathrm{Ca}_{0.02} \mathrm{O}_{1.9}$ sintered conventionally for $4 \mathrm{~h}$ (green) and $8 \mathrm{~h}$ (red) and sintered with MWs for 5 min (blue). The resistivity values were obtained from the respective resistor in the equivalent circuit model and are plotted vs. reciprocal temperature 1/ $T$. properties and unknown ionic pathways across but also along grain boundaries that are contributing and being averaged in the grain boundary response measured by impedance spectroscopy in a macroscopic ceramic sample [32,56-58].

In Fig. 9 we demonstrate that different sintering procedures alter the GB resistivity only slightly and the conventional $8 \mathrm{~h}$ sintering process appears to be optimal for the lowest GB resistivity measured. Since the GB resistivity of MW sintered ceramics is only marginally higher than for conventional sintering, we conclude that the MW sintering processes may be relevant for potential industrial applications due to the massive time and energy savings despite the small tradeoff for a slightly higher resistivity. The bulk resistivity values shown in Fig. 10 indicate a higher resistivity for the Sm-doped $\mathrm{Ce}_{0.85} \mathrm{Sm}_{0.15} \mathrm{O}_{1.925}$ ceramic, which may be associated with the slightly smaller doping level. The lowest bulk resistivity is displayed again by the $8 \mathrm{~h}$ conventionally sintered co-doped $\mathrm{Ce}_{0.8} \mathrm{Sm}_{0.18} \mathrm{Ca}_{0.02} \mathrm{O}_{1.9}$ ceramic, equivalent to the GB resistivity.

The GB and bulk resistivity data for $\mathrm{Ce}_{0.8} \mathrm{Sm}_{0.18} \mathrm{Ca}_{0.02} \mathrm{O}_{1.9}$ ceramics sintered with MW radiation for various amounts of time are summarized in Figs. 11 and 12. The data are displayed over a large temperature range to include the operation temperature of IT-SOFCs. It is noted that the bulk resistivity ap-

pears approximately identical for the different sintering times, whereas the GB resistivity seems to change due to the different heat exposure. This indicates that the densification sintering process serves the intended purpose to only modify the microstructure which is related to the GB behavior, but does not affect the intrinsic bulk properties. Changes in the

Table 1 - Total resistivity $\rho$ and conductivity $\sigma\left(\mathrm{GB}+\right.$ bulk) at $300{ }^{\circ} \mathrm{C}$ and $500{ }^{\circ} \mathrm{C}$, and activation energies for $\mathrm{Ce}_{0.85} \mathrm{Sm}_{0.15} \mathrm{O}_{1.925}$ and $\mathrm{Ce}_{0.8} \mathrm{Sm}_{0.18} \mathrm{Ca}_{0.02} \mathrm{O}_{1.9}$ ceramics sintered at $1450{ }^{\circ} \mathrm{C}$ by different techniques (Conventional \& $\mathrm{MW}$ ) and for different amounts of time.

(A)

\begin{tabular}{|c|c|c|c|c|c|}
\hline Composition & \multicolumn{2}{|c|}{ Conv. sintering } & $\rho$ (tot.) $300^{\circ} \mathrm{C}$ in $\Omega \mathrm{cm}$ & \multicolumn{2}{|c|}{$\sigma$ (tot.) $300{ }^{\circ} \mathrm{C}(\Omega \mathrm{cm})^{-1}$} \\
\hline $\mathrm{Ce}_{0.85} \mathrm{Sm}_{0.15} \mathrm{O}_{1.925}$ & \multicolumn{2}{|c|}{$4 \mathrm{~h}$} & $1.62 \cdot 10^{5}$ & \multicolumn{2}{|c|}{$6.16 \cdot 10^{-6}$} \\
\hline $\mathrm{Ce}_{0.8} \mathrm{Sm}_{0.18} \mathrm{Ca}_{0.02} \mathrm{O}_{1.9}$ & \multicolumn{2}{|c|}{$4 \mathrm{~h}$} & $2.08 \cdot 10^{4}$ & \multicolumn{2}{|c|}{$4.81 \cdot 10^{-5}$} \\
\hline $\mathrm{Ce}_{0.8} \mathrm{Sm}_{0.18} \mathrm{Ca}_{0.02} \mathrm{O}_{1.9}$ & \multicolumn{2}{|c|}{$8 \mathrm{~h}$} & $2.01 \cdot 10^{4}$ & \multicolumn{2}{|c|}{$4.97 \cdot 10^{-5}$} \\
\hline \multicolumn{6}{|l|}{ (B) } \\
\hline Composition & MW sintering & $\begin{array}{c}\rho \text { (tot.) } 300^{\circ} \mathrm{C} \\
\text { in } \Omega \mathrm{cm}\end{array}$ & $\begin{array}{c}\sigma \text { (tot.) } 300^{\circ} \mathrm{C} \\
\text { in }(\Omega \mathrm{cm})^{-1}\end{array}$ & $\begin{array}{c}\rho \text { (tot.) } 500^{\circ} \mathrm{C} \\
\text { in } \Omega \mathrm{cm}\end{array}$ & $\begin{array}{c}\sigma \text { (tot.) } 500^{\circ} \mathrm{C} \\
\text { in }(\Omega \mathrm{cm})^{-1}\end{array}$ \\
\hline $\mathrm{Ce}_{0.85} \mathrm{Sm}_{0.15} \mathrm{O}_{1.925}$ & $5 \min$ & $1.02 \cdot 10^{5}$ & $9.80 \cdot 10^{-6}$ & $8.92 \cdot 10^{2}$ & $1.12 \cdot 10^{-3}$ \\
\hline $\mathrm{Ce}_{0.8} \mathrm{Sm}_{0.18} \mathrm{Ca}_{0.02} \mathrm{O}_{1.9}$ & $30 \mathrm{~min}$ & $5.77 \cdot 10^{4}$ & $1.73 \cdot 10^{-5}$ & $5.58 \cdot 10^{2}$ & $1.79 \cdot 10^{-3}$ \\
\hline $\mathrm{Ce}_{0.8} \mathrm{Sm}_{0.18} \mathrm{Ca}_{0.02} \mathrm{O}_{1.9}$ & $60 \mathrm{~min}$ & $1.04 \cdot 10^{5}$ & $9.62 \cdot 10^{-6}$ & $1.18 \cdot 10^{3}$ & $8.48 \cdot 10^{-4}$ \\
\hline
\end{tabular}

(C)

Composition

Conv.sintering

$T_{0}$ (bulk) in Kelvin

$E_{\mathrm{A}}$ (bulk) in $\mathrm{eV}$

$T_{0}(\mathrm{~GB})$ in Kelvin

$E_{\mathrm{A}}(\mathrm{GB})$ in $\mathrm{eV}$

$\mathrm{Ce}_{0.85} \mathrm{Sm}_{0.15} \mathrm{O}_{1.925}$
$\mathrm{Ce}_{0.8} \mathrm{Sm}_{0.18} \mathrm{Ca}_{0.02} \mathrm{O}_{1.9}$

$4 \mathrm{~h}$

9555

10,030

$4 \mathrm{~h}$

9962

0.82
0.87
0.86

10,850

12,470

11,810

0.94

$\mathrm{Ce}_{0.8} \mathrm{Sm}_{0.18} \mathrm{Ca}_{0.02} \mathrm{O}_{1.9}$

$8 \mathrm{~h}$

0.86

1.08

(D)

Composition

MW sintering

$T_{0}$ (bulk) in Kelvin

$E_{\mathrm{A}}$ (bulk) in eV

$T_{o}(\mathrm{~GB})$ in Kelvin

$E_{\mathrm{A}}(\mathrm{GB})$ in $\mathrm{eV}$

$\mathrm{Ce}_{0.8} \mathrm{Sm}_{0.18} \mathrm{Ca}_{0.02} \mathrm{O}_{1.9}$

$\mathrm{Ce}_{0.8} \mathrm{Sm}_{0.18} \mathrm{Ca}_{0.02} \mathrm{O}_{1.9}$

$\mathrm{Ce}_{0.8} \mathrm{Sm}_{0.18} \mathrm{Ca}_{0.02} \mathrm{O}_{1.9}$
9671

9528

8507
0.83
0.82

0.73
9929

12,310

11,470
0.86

1.06 0.99 


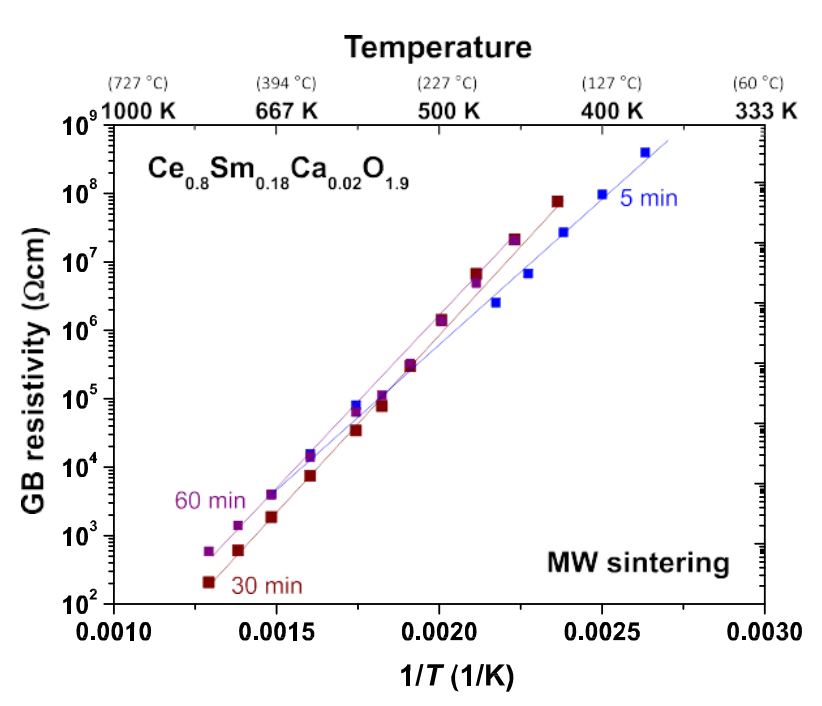

Fig. 11 - GB resistivity values from equivalent circuit fits for $\mathrm{Ce}_{0.8} \mathrm{Sm}_{0.18} \mathrm{Ca}_{0.02} \mathrm{O}_{1.9}$ ceramics $\mathrm{MW}$ sintered for $5 \mathrm{~min}$ (blue), $30 \mathrm{~min}$ (brown) and $60 \mathrm{~min}$ (violet). The resistivity values were obtained from the respective resistor in the equivalent circuit model and are plotted vs. reciprocal temperature $1 / T$.

bulk resistivity would indicate a modification of the intrinsic bulk properties, which would be an unwanted effect of the sintering process. Since we do not observe bulk changes our sintering process may be regarded as a viable ceramic processing step.

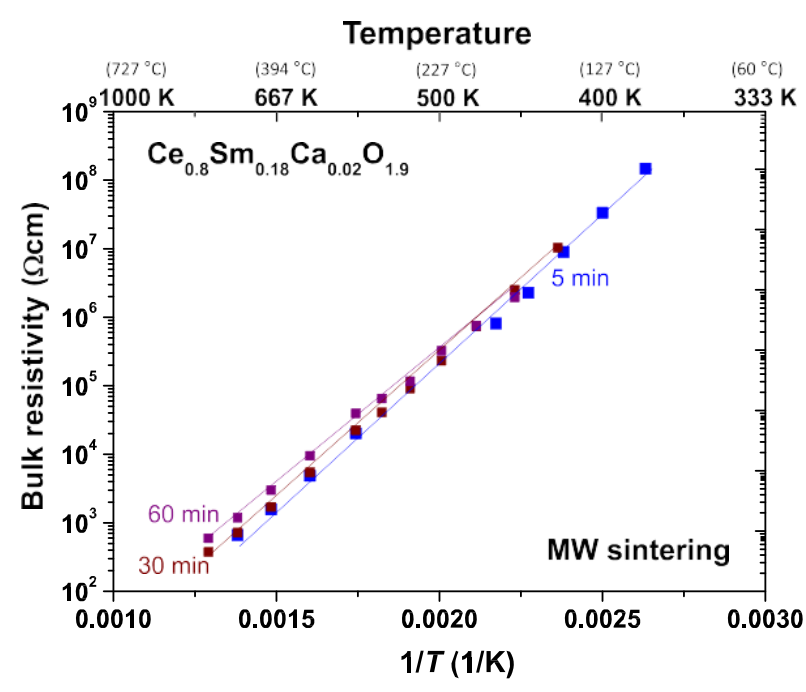

Fig. 12 - Bulk resistivity values from equivalent circuit fits for $\mathrm{Ce}_{0.8} \mathrm{Sm}_{0.18} \mathrm{Ca}_{0.02} \mathrm{O}_{1.9}$ ceramics MW sintered for 5 min (blue), $30 \mathrm{~min}$ (brown) and $60 \mathrm{~min}$ (violet). The resistivity values were obtained from the respective resistor in the equivalent circuit model and are plotted vs. reciprocal temperature $1 / T$.
To summarize, the exceptionally low resistivity values for GB and bulk presented here are in good agreement with previous work on mechano-synthesized samples of the same composition [27]. The absolute values of GB resistivity + bulk resistivity confirm exceptionally low resistivity for oxygen ionic charge transport in our Sm and Ca co-doped ceria ceramics. Sm and Ca co-doping, MW synthesis and MW sintering seem to be promising and complementary strategies to obtain highly ionically conducting materials for potential application as a solid electrolyte in IT-SOFCs using environmentally friendly processing routes.

Effects of dc-bias and gas atmosphere on the ionic conductivity Since the low oxygen ion resistivity discussed above would be relevant for industrial application, it is important to confirm the purely ionic character of the conduction. A possible electronic contribution is unwanted and would harm the operation of the electrolyte in a potential IT-SOFC. Therefore, we have studied the effect of a dc-bias voltage signal $(0 \mathrm{~V}, 1 \mathrm{~V}, 2 \mathrm{~V}$, $5 \mathrm{~V}, 10 \mathrm{~V}$ and $20 \mathrm{~V}$ ), which was super-imposed on the standard $100 \mathrm{mV}$ ac voltage signal. Fig. 13 demonstrates that the additional dc-bias voltage leads to a decreasing GB resistance when increasing the dc-bias, as indicated by a decreasing size of the GB semicircle in the $-Z^{\prime \prime}$ vs $Z^{\prime}$ complex plane plot at $473 \mathrm{~K}$ $\left(200{ }^{\circ} \mathrm{C}\right.$ ) for a $\mathrm{Ce}_{0.8} \mathrm{Sm}_{0.18} \mathrm{Ca}_{0.02} \mathrm{O}_{1.9}$ ceramic sample, MW sintered at $1450{ }^{\circ} \mathrm{C}$ for $30 \mathrm{~min}$. The observed effects also occurred in all other samples (not shown). This dc-bias dependence of the GB resistivity is a typical feature of ionic conductors, where the GBs are often interpreted in terms of charge blocking Schottky-type barriers. On the other hand, the ionic conduction within the grain interior areas is unaffected by the

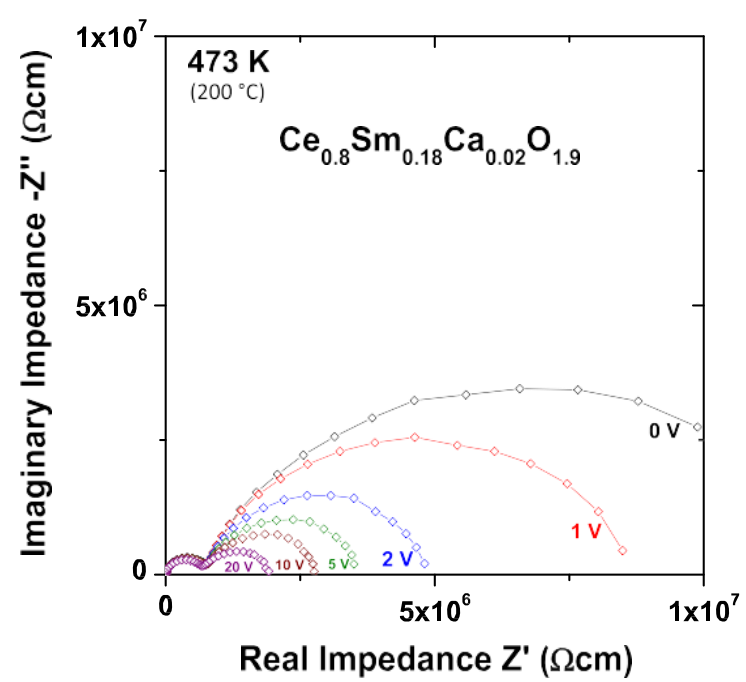

Fig. 13 - Complex impedance plot of $-Z^{\prime \prime}$ vs. $\boldsymbol{Z}$ at $473 \mathrm{~K}(200$ ${ }^{\circ} \mathrm{C}$ ) for a $\mathrm{Ce}_{0.8} \mathrm{Sm}_{0.18} \mathrm{Ca}_{0.02} \mathrm{O}_{1.9}$ ceramic, MW sintered at 1450 ${ }^{\circ} \mathrm{C}$ for $30 \mathrm{~min}$. The data were collected with various dc bias voltages $(0 \mathrm{~V}, 1 \mathrm{~V}, 2 \mathrm{~V}, 5 \mathrm{~V}, 10 \mathrm{~V}, 20 \mathrm{~V})$ superimposed over the regular $100 \mathrm{mV}$ ac voltage signal as indicated. The figure demonstrates the dc bias dependence of the GB resistance but not the bulk resistance. This is consistent with oxygen ion conduction, where the GB areas act as Schottky type barriers for ionic charge transport. Open symbols and solid lines represent measured data. 
dc-bias as expected. This is indicated in Fig. 13 by an approximately constant size of the bulk semicircle.

Another common test for ionic conductivity is the dependence of the resistivity upon the oxygen partial pressure. In case of an electronic contribution from a hypothetical $\mathrm{Ce}^{3+} /$ $\mathrm{Ce}^{4+}$ mixed valence state the resulting resistivity is expected to change perceptibly with the oxygen partial pressure [59]. This is due to the strong dependence of the resistivity on the balance between the redox-pair $\mathrm{Ce}^{3+} / \mathrm{Ce}^{4+}$. Under air gas flow with increased oxidation the expected trend would be towards $\mathrm{Ce}^{4+}$ and increasing resistance, whereas partial reduction under $\mathrm{N}_{2}$ gas flow would result in a trend towards $\mathrm{Ce}^{3+}$ and decreasing resistance. No significant resistivity changes were observed by measuring the impedance of a $4 \mathrm{~h}$ conventionally synthesized $\mathrm{Ce}_{0.8} \mathrm{Sm}_{0.18} \mathrm{Ca}_{0.02} \mathrm{O}_{1.9}$ ceramic under air and nitrogen gas flows. The same effect was also observed in a MW sintered sample investigated under the same conditions. Fig. 14 shows the complex impedance plots at $393 \mathrm{~K}\left(120^{\circ} \mathrm{C}\right)$, where only marginal changes in the resistivity are indicated. These subtle changes can be interpreted as a result of a small temperature discrepancy during the two measurements, and a significant electronic contribution is not indicated. On the other hand, the low frequency interface contribution shows a clear change with the air or $\mathrm{N}_{2}$ gas flow, which we explain in terms of the diffusive type charge transport across the sample electrode interface. It may be concluded that the oxidation state of $\mathrm{Ce}$ is predominantly $\mathrm{Ce}^{4+}$ and a hypothetical $\mathrm{Ce}^{3+}$ oxidation state cannot be confirmed within experimental error.

In Figs. 13 and 14 all 3 relaxation processes (bulk, GB, interface) are clearly visible at the same time only around the

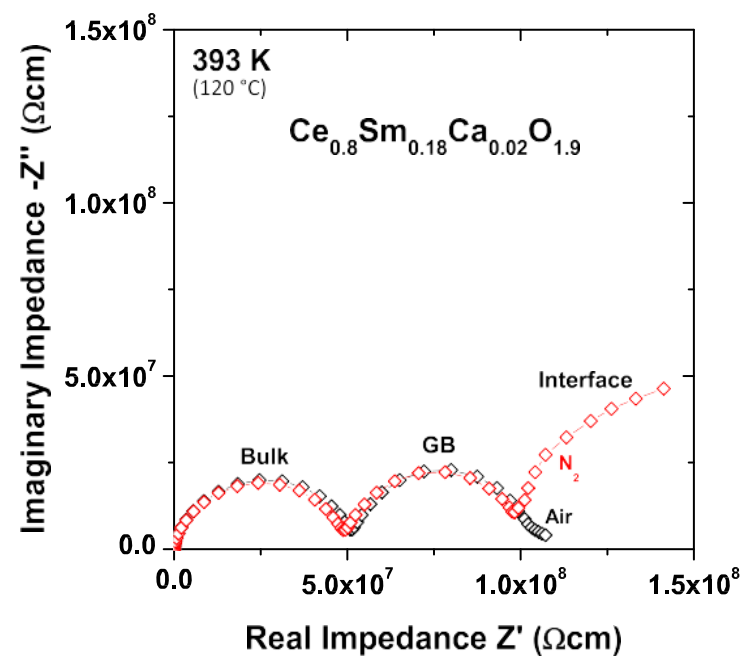

Fig. 14 e Complex impedance plot of $-Z^{00}$ vs. $\boldsymbol{Z}$ at $393 \mathrm{~K}$ $\left(120^{\circ} \mathrm{C}\right.$ ) under Air (black) and $\mathrm{N}_{2}$ (red) gas flow for a $\mathrm{Ce}_{0.8} \mathrm{Sm}_{0.18} \mathrm{Ca}_{0.02} \mathrm{O}_{1.9}$ ceramic, conventionally sintered at $1450{ }^{\circ} \mathrm{C}$ for $4 \mathrm{~h}$. The figure demonstrates marginal dependence of the bulk and GB resistivity on $N_{2}$ or air gas flow. This is consistent with oxygen ion conductivity, and no perceptible $\mathrm{Ce}^{3 \mathrm{p}}$ concentration is evident to open an

electronic conduction pathway. Open symbols and solid lines represent measured data. selected temperatures due the equivalent argument brought forward above in context with Fig. 6: By increasing the temperature all dielectric relaxations shift to higher frequencies, because all 3 relaxation processes are Arrhenius activated and get accelerated at higher temperature [29]. The effect of DC bias and different atmosphere on all 3 relaxations can be fully visualized only at the selected optimum temperatures.

To summarize, the findings of a typical interface "pike" in the $-Z^{\prime \prime}$ vs $Z^{\prime}$ plots (Fig. 6), the linear increase of $\varepsilon^{\prime}$ with decreasing $f$ in the $\varepsilon^{\prime}$ vs $f$ curves (Fig. 8), the typical activation energies in the range of $E_{\mathrm{A}} \approx 0.8-1 \mathrm{eV}$ (Table 1 ), the dc bias dependence of only the GB resistance but not the bulk (Fig. 13) and the negligible effect of the gas flow atmosphere on the resistivity (Fig. 14), are all consistent with pure oxygen ion conductivity without any significant electronic contribution. Previous reports have detected an additional or even dominating electronic contribution in doped ceria ceramics [60], which we have not observed here in our work. We believe that our samples may be oxygenated to a high extent with almost exclusive $\mathrm{Ce}^{4 \mathrm{p}}$ valence state, or in other words our samples may strongly tend towards a higher oxidation state of $\mathrm{Ce}^{4+}$ within the possible redox-pair $\mathrm{Ce}^{3+} / \mathrm{Ce}^{4+}$.

\section{Conclusions}

MW synthesized $\mathrm{Ce}_{0.8} \mathrm{Sm}_{0.18} \mathrm{Ca}_{0.02} \mathrm{O}_{1.9}$ ceramics exhibit exceptionally high oxygen ion conductivity without any significant electronic contribution. MW assisted sintering leads to only slightly increased resistivity, but offers massive energy and time saving for potential industrial production processes. Exceptionally high oxygen ion conductivity without any significant electronic contribution was found in MW synthesized and MW sintered pellets, where the total resistivity, composed of grain boundary and bulk contributions, was in the range of 0.5 - $1 \mathrm{k} \Omega$ at $500{ }^{\circ} \mathrm{C}$. Sm- and Ca co-doped ceria may be regarded strong candidates for electrolyte materials in ITSOFCs. MW synthesis and Ca doping of ceria ceramics can effectively reduce the resistance of the GBs, which constitute barriers for oxygen ion charge transport. The exact mechanism for this efficient reduction of the GB resistivity is unclear at this point and may deserve further research work.

\section{Acknowledgments}

J.P.-G. acknowledges financial help from the Community of Madrid (Materyener S2009/PPQ-1626) and a PhD scholarship from the Universidad Complutense de Madrid. R.S. wishes to acknowledge the MICINN/MINECO in Spain for granting a Ramon y Cajal Fellowship. Furthermore, this work was supported by the MICINN/MINECO through grant no. MAT 200731034 and by the European Union through the FP7-PEOPLE2007-1-1-ITN SOPRANO network. The authors wish to express their gratitude to Jacobo Santamaria and Carlos Leon for allowing use of and for assistance with the Novocontrol impedance spectroscopy facilities. Thanks to María Jose Torralvo for carrying out BET measurements. 


\section{References}

[1] Vivanpatarakij S, Aiouache F, Assabumrungrat S. Performance of an improved combination unit of $\mathrm{Pd}-$ membrane methane steam reformer and intermediate temperature solid oxide fuel cell (C-Pd-ITSOFC). Int J Hydrogen Energy 2015;40:1894-901.

[2] Zhu B. Advantages of intermediate temperature solid oxide fuel cells for tractionary applications. J Power Sources 2001;93:82-6.

[3] Brett DJL, Atkinson A, Brandon NP, Skinner SJ. Intermediate temperature solid oxide fuel cells. Chem Soc Rev 2008;37:1568-78.

[4] Dokiya M. SOFC system and technology. Solid State Ionics 2002;152e153:383-92.

[5] Morales JCR. Pilas de combustible de oxidos sólidos (SOFC): Centro de la Cultura Popular Canaria. 2008.

[6] Zhi M, Lee S, Miller N, Menzler NH, Wu N. An intermediatetemperature solid oxide fuel cell with electrospun nanofiber cathode. Energy Environ Sci 2012;5:7066-71.

[7] Raza R, Wang X, Ma Y, Liu X, Zhu B. Improved ceriaecarbonate composite electrolytes. Int J Hydrogen Energy 2010;35:2684-8.

[8] Skinner SJ, Kilner JA. Oxygen ion conductors. Mater Today 2003;6:30-7.

[9] Garcia-Barriocanal J, Rivera-Calzada A, Varela M, Sefrioui Z, Iborra E, Leon $\mathrm{C}$, et al. Colossal ionic conductivity at interfaces of epitaxial $\mathrm{ZrO}_{2}: \mathrm{Y}_{2} \mathrm{O}_{3} / \mathrm{SrTiO}_{3}$ heterostructures.

Science 2008;321:676-80.

[10] Rivera-Calzada A, Diaz-Guillen MR, Dura OJ, SanchezSantolino G, Pennycook TJ, Schmidt R, et al. Tailoring interface structure in highly strained YSZ/STO heterostructures. Adv Mater 2011;23:5268-74.

[11] Rivera A, Santamaría J, León C. Electrical conductivity relaxation in thin-film yttria-stabilized zirconia. Appl Phys Lett 2001;78:610-2.

[12] Qian J, Tao Z, Xiao J, Jiang G, Liu W. Performance improvement of ceria-based solid oxide fuel cells with yttriastabilized zirconia as an electronic blocking layer by pulsed laser deposition. Int J Hydrogen Energy 2013;38:2407-12.

[13] Sammes N, Smirnova A, Vasylyev O. Fuel cell technologies: state and perspectives. In: Proceedings of the NATO advanced research workshop on fuel cell technologies: state and perspectives. Berlin: Spinger; 2005.

[14] Andersson DA, Simak SI, Skorodumova NV, Abrikosov IA, Johansson B. Optimization of ionic conductivity in doped ceria. PNAS 2006;103:3518-21.

[15] Inaba H, Tagawa H. Ceria-based solid electrolytes. Solid State Ionics 1996;83:1-16.

[16] Tuller H, Nowick A. Doped ceria as a solid oxide electrolyte. J Electrochem Soc 1975;122:255-9.

[17] Kharton VV, Figueiredo FM, Navarro L, Naumovich EN, Kovalevsky AV, Yaremchenko AA, et al. Ceria-based materials for solid oxide fuel cells. J Mater Sci 2001;36:110517.

[18] Mogensen M, Sammes NM, Tompsett GA. Physical, chemical and electrochemical properties of pure and doped ceria. Solid State Ionics 2000;129:63-94.

[19] Khan MA, Raza R, Lima RB, Chaudhry MA, Ahmed E, Abbas G. Comparative study of the nano-composite electrolytes based on samaria-doped ceria for low temperature solid oxide fuel cells (LT-SOFCs). Int J Hydrogen Energy 2013;38:16524-31.

[20] Choi Y-G, Park J-Y, Son J-W, Lee J-H, Je H-J, Kim B-K, et al. Ceria-based electrolyte reinforced by sol-gel technique for intermediate-temperature solid oxide fuel cells. Int J Hydrogen Energy 2013;38:9867-72.
[21] Wu Y-C, Lin C-C. The microstructures and property analysis of aliovalent cations $\left(\mathrm{Sm}^{3+}, \mathrm{Mg}^{2+}, \mathrm{Ca}^{2+}, \mathrm{Sr}^{2+}, \mathrm{Ba}^{2+}\right)$ co-doped ceria-base electrolytes after an aging treatment. Int $\mathrm{J}$ Hydrogen Energy 2014;39:7988-8001.

[22] Tao Z, Hou G, Xu N, Zhang Q. A highly coking-resistant solid oxide fuel cell with a nickel doped ceria: $\mathrm{Ce}_{1-x} \mathrm{Ni}_{x} \mathrm{O}_{2-\mathrm{y}}$ reformation layer. Int J Hydrogen Energy 2014;39:5113-20.

[23] Jaiswal N, Upadhyay S, Kumar D, Parkash O. Sm ${ }^{3 p}$ and $\mathrm{Sr}^{2 p}$ co-doped ceria prepared by citrateenitrate auto-combustion method. Int J Hydrogen Energy 2014;39:543-51.

[24] Jaiswal N, Upadhyay S, Kumar D, Parkash O. Ionic conduction in $\mathrm{Mg}^{2 \mathrm{~b}}$ and $\mathrm{Sr}^{2 \mathrm{~b}}$ co-doped ceria/carbonates nanocomposite electrolytes. Int J Hydrogen Energy 2015;40:3313-20.

[25] Shannon R. Revised effective ionic radii and systematic studies of interatomic distances in halides and chalcogenides. Acta Cryst A 1976;32:751-67.

[26] Crabtree RH. Energy production and storage: inorganic chemical strategies for a warming world. Wiley; 2013.

[27] Basu S, Khamrui S, Bandyopadhyay NR. Sintering and electrical properties of Ce0.75Sm0.2Li0.05O1.95. Int J Hydrogen Energy 2014;39:17429-33.

[28] Zhu S, Wang Y, Rao Y, Zhan Z, Xia C. Chemically-induced mechanical unstability of samaria-doped ceria electrolyte for solid oxide electrolysis cells. Int J Hydrogen Energy 2014;39:12440-7.

[29] Prado-Gonjal J, Schmidt R, Espíndola-Canuto J, RamosAlvarez P, Morán E. Increased ionic conductivity in microwave hydrothermally synthesized rare-earth doped

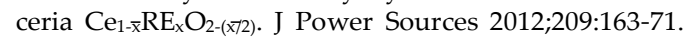

[30] Moure A, Moure C, Tartaj J. A significant improvement of the processing and electric properties of $\mathrm{CeO}_{2}$ co-doped with $\mathrm{Ca}$ and Sm by mechanosynthesis. J Power Sources 2011;196:10543-9.

[31] Moure A, Tartaj J, Moure C. Synthesis, sintering and electrical properties of yttriaecalcia-doped ceria. J Eur Ceram Soc 2009;29:2559-65.

[32] Guo X, Waser R. Electrical properties of the grain boundaries of oxygen ion conductors: acceptor-doped zirconia and ceria. Prog Mater Sci 2006;51:151.

[33] Sun C, Li H, Chen L. Nanostructured ceria-based materials: synthesis, properties, and applications. Energy Environ Sci 2012;5:8475-505.

[34] Prado-Gonjal J, Schmidt R, Moran E. Microwave-assisted synthesis and characterization of perovskite oxides. In: Zhang J, Li H, editors. Perovskite: crystallography, chemistry and catalytic performance. Nova Science Pub Incorporated; 2012. p. 117.

[35] Borrell A, Salvador MD, Peñaranda-Foix FL, Cátala-Civera JM. Microwave sintering of zirconia materials: mechanical and microstructural properties. Int J Appl Ceram Technol 2013;10:313-20.

[36] Schmidt R, Prado-Gonjal J, Moran E. Microwave-assisted hydrothermal synthesis of nanoparticles. In: Kharisov B, Kharissova O, Ortiz-Mendez U, editors. CRC concise encyclopedia of nanotechnology. Boca Raton (USA): CRC Press Taylor \& Francis Group; 2015.

[37] Kim G, Lee N, Kim K-B, Kim B-K, Chang H, Song S-J, et al. Various synthesis methods of aliovalent-doped ceria and their electrical properties for intermediate temperature solid oxide electrolytes. Int J Hydrogen Energy 2013;38:1571-87.

[38] Komarneni S. Nanophase materials by hydrothermal, microwave-hydrothermal and microwave-solvothermal methods. Curr Sci 2003;85:1730.

[39] Oghbaei M, Mirzaee O. Microwave versus conventional sintering: a review of fundamentals, advantages and applications. J Alloys Comp 2010;494:175-89.

[40] Menezes RR, Souto PM, Kiminami RHGA. Microwave fast sintering of ceramic materials. In: Lakshmanan A, editor. 
Sintering of ceramics e new emerging techniques. Intech; 2012. p. 3-26.

[41] Meng J, Pan Y-B, Luo Q, An X-H, Liu Y, Li Q, et al. A comparative study on effect of microwave sintering and conventional sintering on properties of $\mathrm{NdeMgeNieFe} 3 \mathrm{O}_{4}$ hydrogen storage alloy. Int J Hydrogen Energy 2010;35:83106.

[42] Brandão AD, Antunes I, Frade JR, Torre J, Mikhalev SM, Fagg DP. Mechanochemical preparation, sintering aids and hybrid microwave sintering in the proton conductor $\mathrm{Sr}_{0.02} \mathrm{La}_{0.98} \mathrm{Nb}_{1-\mathrm{x}} \mathrm{V}_{\mathrm{x}} \mathrm{O}_{4-\mathrm{d}}, \mathrm{x}=0$, 0.15. Int J Hydrogen Energy 2012;37:7252-61.

[43] Prado-Gonjal J, Schmidt R, Morán E. Microwave-assisted routes for the synthesis of complex functional oxides. Inorganics 2015;3:101.

[44] Carvajal JR. FULLPROF: a program for rietveld refinement and pattern matching analysis. Abstracts of the satellite meeting on powder diffraction of the XV Congress of the IUCr. 1990.

[45] Brunauer S, Emmett PH, Teller E. Adsorption of gases in multimolecular layers. J Am Chem Soc 1938;60:309-19.

[46] Bae Y-S, Yazaydin AG, Snurr RQ. Evaluation of the BET method for determining surface areas of MOFs and zeolites that contain ultra-micropores. Langmuir 2010;26:5475-83.

[47] Rouquerol J, Rouquerol F, Sing KSW. Adsorption by powders and porous solids: principles, methodology and applications. Elsevier Science; 1998.

[48] Sing K. Reporting physisorption data for gas/solid systems with special reference to the determination of surface area and porosity. Pure Appl Chem 1985;57:603-19.

[49] Irvine JTS, Sinclair DC, West AR. Electroceramics: characterization by impedance spectroscopy. Adv Mater 1990;2:132-8.

[50] Barsukov E, Macdonald J. Impedance spectroscopy: theory, experiment and applications. Hoboken. John Wiley \& Sons Inc.; 2005.
[51] Funke K, Hoppe R. Jump-relaxation model yields KohlrauschWilliams-Watts behaviour. Solid State Ionics 1990;40-41:200.

[52] Schmidt R, Eerenstein W, Winiecki T, Morrison FD, Midgley PA. Impedance spectroscopy of epitaxial multiferroic thin films. Phys Rev B 2007;75:245111.

[53] Boukamp BA. Electrochemical impedance spectroscopy in solid state ionics: recent advances. Solid State Ionics 2004;169:65-73.

[54] Ramesh S, Kumar VP, Kistaiah P, Reddy CV. Preparation, characterization and thermo electrical properties of codoped $\mathrm{Ce}_{0.8-\mathrm{x}} \mathrm{Sm}_{0.2} \mathrm{Ca}_{\mathrm{x}} \mathrm{O}_{2-\mathrm{x}}$ materials. Solid State Ionics 2010;181:86-91.

[55] Wang B, Lin ZA. Schottky barrier based model for the grain size effect on oxygen ion conductivity of acceptor-doped $\mathrm{ZrO}_{2}$ and $\mathrm{CeO}_{2}$. Int $\mathrm{J} H y d r o g e n$ Energy 2014;39:14334-41.

[56] Garcia-Barriocanal J, Rivera-Calzada A, Varela M, Sefrioui Z, Díaz-Guillen MR, Moreno KJ, et al. Tailoring disorder and dimensionality: strategies for improved solid oxide fuel cell electrolytes. ChemPhysChem 2009;10:1003-11.

[57] Kosacki I, Rouleau CM, Becher PF, Bentley J, Lowndes DH. Nanoscale effects on the ionic conductivity in highly textured YSZ thin films. Solid State Ionics 2005;176:1319-26.

[58] Peters A, Korte C, Hesse D, Zakharov N, Janek J. Ionic conductivity and activation energy for oxygen ion transport in superlattices - the multilayer system CSZ $\left(\mathrm{ZrO}_{2} \mathrm{p} \mathrm{CaO}\right) /$ $\mathrm{Al}_{2} \mathrm{O}_{3}$. Solid State Ionics 2007;178:67-76.

[59] Kim S, Maier J. Partial electronic and ionic conduction in nanocrystalline ceria: role of space charge. J Eur Ceram Soc 2004;24:1919-23.

[60] Srivastava M, Kumar K, Jaiswal N, Singh NK, Kumar D, Parkash O. Enhanced ionic conductivity of co-doped ceria solid solutions and applications in IT-SOFCs. Ceram Intern 2014;40:10901-6. 